$$
\begin{gathered}
\text { 서울로 } 7017 \text { 방문자들의 이용행태 분석 } \\
\text {-텍스트 마이닝과 소셜 네트워크 분석을 중심으로- } \\
\text { 우경숙 - 서주환 }
\end{gathered}
$$

"경희대학교 일반대학원 환경조경학과 강사·"경희대학교 예술·디자인대학 환경조경디자인학과 교수

\title{
Analysis of Behavior of Seoullo 7017 Visitors - With a Focus on Text Mining and Social Network Analysis -
}

\author{
Woo, Kyung-Sook ${ }^{*}$ Suh, Joo-Hwan ${ }^{* *}$ \\ "Lecturer, Graduate School of Landscape Architecture, Kyung Hee University \\ ${ }^{* *}$ Professor, Dept. of Landscape Architecture, Kyung Hee University
}

\begin{abstract}
The purpose of this study is to analyze the usage behavior of Seoullo 7017, the first public garden in Korea, to understand the usage status by analyzing blogs, and to present usage behavior and improvement plans for Seoullo 7017. From June 2017 to May 2020, after Seoullo 7017 was open to citizens, character data containing 'Seoullo 7017' in the title and contents of NAVER and - DAUM blogs were converted to text mining and socialization, a Big Data technique. The analysis was conducted using social network analysis. The summary of the research results is as follows. First of all, the ratio of men and women searching for Seoullo 7017 online is similar, and the regions that searched most are in the order of Seoul and Gyeonggi, and those in their 40s and 50s were the most interested. In other words, it can be seen that there is a lack of interest in regions other than Seoul and Gyeonggi and among those in their 10s, 20s, and 30s. The main behaviors of Seoullo 7017 are' night view' and 'walking', and the factors that affect culture and art are elements related to culture and art. If various programs and festivals are opened and actively promoted, the main behavior will be more varied. On the other hand, the main behavior that the users of Seoullo 7017 want is 'sit', which is a static behavior, but the physical conditions are not sufficient for the behavior to occur. Therefore, facilities that can cause sitting behavior, such as shades and benches must be improved to meet the needs of visitors. The peculiarity of the change in the behavior of Seoullo 7017 is that it is recognized as a good place to travel alone and a good place to walk alone as a public multi-use facility and group activities are restricted due to COVID-19. Accordingly, in a situation like the COVD-19 pandemic, more diverse behaviors can be derived in facilities where people can take a walk, etc., and the increase of various attractions and the satisfaction of users can be increased. Seoullo 7017, as Korea's first public pedestrian area, was created for urban regeneration and the efficient use of urban resources in areas beyond the meaning of public spaces and is a place with various values such as history, nature, welfare, culture, and tourism. However, as a result of the use behavior analysis, various behaviors did not occur in Seoullo 7017 as expected, and elements that hinder those major behaviors were derived. Based on these research results, it is necessary to understand the usage behavior of Seoullo 7017 and to establish a plan for spatial system
\end{abstract}

Corresponding author: Joo-Hwan Suh, Professor, Dept. of Landscape Architecture, Kyung Hee University, Yong-in 17104, Korea, Tel.: +82-31-201-2680, E-mail: meek1126@naver.com 
and facility improvement, so that Seoullo 7017 can be an important place for urban residents and a driving force to revitalize the city.

\section{Key words: Seoullo 7017, Usage Behavior, Text Mining, Social Network Analysis}

\section{국문초록}

본 연구는 국내 최초의 공중보행로인 서울로 7017 의 이용행태를 이용객이 자율적으로 서술한 블로그를 분석하여 이용현황을 파악하고, 서울로 7017의 이용행태 및 개선방안을 제시하는 것을 목적으로 하였다. 이에 서울로 7017이 시민에 게 개방된 2017년 6월부터 2020년 5월까지로 검색엔진 NAVER - DAUM의 블로그 제목과 원문에 '서울로 7017'이 포함된 텍스트 데이터를 빅데이터 기법인 텍스트 마이닝(Text Mining)과 소셜 네트워크(Social Network; 사회연결망)분석을 활용하여 분석하였다. 연구결과의 요약은 다음과 같다. 먼저 서울로 7017의 주요 행태는 '야경'과 '걷다'이고, 영향을 미치는 요소는 문화 - 예술과 관련된 요소로 여러 가지 프로그램 및 축제를 이용객의 요구에 맞는 프로그램을 개설하고 적극적으로 알린다면 주요 행태가 더 활발하게 일어나게 할 수 있을 것이다. 한편, 서울로 7017의 이용객들이 원하는 주요행태는 정적 행태인 '앉다'인데, 앉는 행태가 일어나기에 물리적인 조건이 충분하지 않으므로 그늘, 벤치 등 앉는 행태가 일어날 수 있는 시설을 개선하여 방문객의 요구를 충족시킬 수 있을 것이다. 서울로 7017의 행태변화의 특이점으로 코로나19로 인하여 공공다중이용시설 및 집단 활동이 제한되면서 혼자 여행하기 좋은 곳, 혼자 산책하기 좋은 곳으로 인식되고 있다는 점이다. 이에 코로나19와 같은 상황에서 사람들이 산책 등을 할 수 있는 시설, 여러 가지 볼거리 증대 등을 통하여 더 다양한 행태가 도출될 수 있고, 이용객의 만족도를 높일 수 있다.

서울로 7017은 국내 최초의 공중보행로서 공공공간의 의미를 넘어 주변 지역의 도시재생 및 도시자원의 효율적 활용을 위하여 조성되었으며, 역사, 자연, 복지, 문화, 관광자원 등 다양한 가치를 지니고 있는 장소이다. 그러나 이용행태 분석 결과, 서울로 7017에서 다양한 행태가 일어나지 않고 있으며, 주요 행태를 방해하는 요소가 도출되었다. 이러한 연구 결과를 참고하여 서울로 7017의 이용행태를 파악하고, 공간체계 및 시설 개선의 계획을 수립하여 서울로 7017이 도시민들에게 중요한 장소이자 도시를 활성화하는 동력이 될 수 있도록 발전시켜 나가야 할 것이다.

주제어: 서울로 7017 , 이용행태, 텍스트 마이닝, 소설 네트워크 분석

\section{I. 서론}

1970년 개통된 서울역 고가는 차량이 통행하는 곳으로 교통 흐름을 원활하게 하는 고가도로의 일반적인 기능과 서울역사 와 선로 및 부속 시설에 의해 단절된 지역을 잇는 역할을 수행 하였다(Seoullo 7017 white paper). 그러나 1990년대 말부터 시 설의 노후화, 안전 문제 등으로 철거가 제기되었다.

최근 노후화된 도시를 새롭게 변모시키는 도시재생의 일환 으로 많은 계획들이 진행되고 있다. 시대적 흐름에 따라 다른 기능으로 변화되고, 다양한 형태의 공공공간들이 많이 나타나고 있다(Kim, 2019). 이에 서울역 고가도로는 철거하는 대신 보행 길로 활용되는 사업이 추진되었고, 서울로 7017로 거듭났다.

서울로 7017은 하루 39 만명, 75 개 버스 노선이 오가는 서울 역과 4대문 안 도심을 연계하고, 인근 지역 도시재생의 활성화 등의 목표를 추구하고 있어 단순한 건설사업이 아니었다(Seoul lo 7017 white paper). 또한, 도시재생의 일환으로 실시되는 도
시녹화과정은 도시환경의 쾌적성을 높여 이를 도시관광과 연 계함으로써 도시경쟁력에 적잖은 영향을 미치고 있다(Rii and Choi, 2009). 특히 서울로 7017은 주변지역의 17 개의 길로 연결 되어 많은 사람들의 이용이 가능하며, 다양한 행태를 지원할 수 있는 공간으로 개장 3주년을 기점으로 총 2천 470 만명이 방문하였으며, 해를 거듭할수록 방문객이 증가하고 있다(Yna, https://www.yna.co.kr/view/AKR20200518144800004?input= 11 95m, 2020.05.19.). 한편, 서울로 7017과 관련된 선행연구 및 뉴스 기사를 살펴보면 서울로 7017 의 정책에 대한 다각적인 시 각, 장애인이 이용하기 불편한 시설 및 수목고사(Newsis, 201 7; Newdaily, 2017; Yna, 2017; Choung, 2018; Kim, 2018) 등 의 문제점 등 긍정적인 관점과 부정적인 관점이 동시에 제기되 고 있는 실정이다.

서울로 7017의 행태와 관련된 선행연구를 살펴보면, Park et al. (2018)은 도시 재생 프로젝트에 대한 방문객의 인식에 대한 연구가 부족함을 지적하고 IPA기법을 활용하여 서울로 7017 
방문객의 인식 조사를 하였다. 이에 서울로 7017에 대한 서비 스 및 정보제공에 대한 부분에 중점을 두고, 지역 주민들의 복 지 관련 측면 등을 부각하는 서비스를 추가적으로 제시해야 하 며, 야경을 볼 수 있는 시설을 마련하는 방안을 제시하였다. Choung (2018)은 문헌연구와 현장답사를 통해 서울로 7017이 도시관광으로 도약하기 위한 개선방안을 제시하였다. 연구 결 과, 시멘트정원으로 진정성 있는 공공공간으로 교류되지 못하 고 있는 점, 식재 및 화분의 배열의 단점, 벤치 및 그늘 등 휴식 공간 부족, 서울로 7017 과 연관된 관광부속시설의 부족 등의 내용을 도출하였다. Cha et al. (2020)은 서울로 7017에 도입된 식물과 이입식물 특성을 조사·분석하여 이입식물의 제초 작 업 시기와 제초 작업을 줄이기 위한 방안을 제시하였다.

현대의 공공공간은 도시민들에게 자연경관, 휴양 및 레저, 문화생활의 향상 등 복지를 위한 공간으로 인식되고 있으며, 이러한 공공의 성격 때문에 이용객에 대한 연구가 점점 증대하 고 있다(Joo and Kim, 2010). 그러나 서울로 7017의 이용객들 이 어떻게 경험하고 있는지에 대한 연구는 부족하여 이를 파악 하는 연구가 필요하다고 판단하였다. 따라서 본 연구는 서울로 7017의 이용객이 자율적으로 서술한 블로그를 텍스트 마이닝 과 소셜 네트워크 분석을 활용하여 이용현황을 파악하고, 서울 로 7017의 이용 특성 및 개선방안을 제시하는 것을 목적으로 한다. 특히 텍스트 마이닝과 소셜 네트워크 분석은 서울로 7017에서 어떤 원인에 의해서 행태가 나타나는지, 행태에 영향 을 미치는 요소가 무엇인지를 능동적인 자료에 의해 파악할 수 있다. 이는 국내 최초의 공중보행로의 이용 행태를 설명할 수 있는 주요한 자료로서 활용될 수 있으며, 서울로 7017의 이용 특성을 파악하는 하나의 척도로 의미가 있다.

\section{II. 연구대상 및 방법}

\section{1. 연구대상지 선정 및 현황}

대상지는 차량길을 보행길로 재탄생시킨 서울 도시재생사업 의 하나이며, 문화체육관광부. 한국관광공사에서 주체하는 2019 -2020년 '한국관광100선' (Ministry of Culture, Sports and Touri sm, https://www.mcst.go.kr/kor/s_notice/press/pressView.js $\mathrm{p} ? \mathrm{pSeq}=17057$ )에 선정된 서울로 7017로 선정하였다. 서울로 7 017의 공간 조성은 퇴계로 주변, 서울역 광장, 한강대로 주변, 중림동 방향, 만리동 방향, 청파동 방향에서 진입을 할 수 있어 남대문에서 만리동까지 이동할 수 있는 보행길로서의 역할을 한다(Lee, 2019). 또한, 서울로 7017 조경 공사는 보행길에 50 과 228종 24,085 주 수목을 식재하였고, 645 개의 원형화분이 설 치되어 있다. 시작점인 퇴계로와 종점인 만리동 방향으로 가면 서 구기자나무부터 회양목까지 가나다순으로 수목을 식재하였
다(Cha et al., 2020).

서울로 7017 에서 운영되거나 혹은 준비 중인 프로그램은 Table 1 과 같이 행사, 교육, 전시, 공연, 해설, 단체봉사, 개인봉 사로 구분된다. 행사는 주로 지정일에 이루어지며, 이동식 화분 에 파종을 하거나, 나만의 작품활동을 하는 내용의 행사이다. 교육은 종류에 따라 약 일주일에서 4 개월 가량 운영되는데, 여 행에세이를 쓰거나 서울로 식물을 관찰하고 식물도감을 만드 는 등 다양한 프로그램이 운영되고 있다. 해설은 서울로 및 인 근지역의 생태, 역사, 문화에 관한 해설과 함께 서울로 7017을 산책하는 프로그램이다. 이 밖에도 개인 혹은 가족이 화분에 가 드닝하며 자원봉사에 참여할 수 있는 프로그램이 운영되고 있다.

\section{2. 연구방법}

1) 데이터 수집

본 연구를 위한 데이터 수집은 서울로 7017이 시민에게 개방 된 2017년 6월부터 2020년 5월까지 기간을 한정하고, 검색엔진 NAVER - DAUM의 블로그 제목과 원문에 '서울로 7017'이 포함된 텍스트 데이터이다. 블로그 수집 및 정제는 빅데이터 프로그램 텍스톰(TEXTOM)을 활용하였다.

2) 텍스트마이닝 분석(Text Mining Analysis)

(1) 주요 행태 키워드 분석

데이터 수집에서 높은 빈도로 도출된 상위 100 개의 키워드 중 기존 연구(Woo and Suh, 2020)를 참조하여 사람의 움직임

Table 1. Seoullo 7017 Program

\begin{tabular}{c|l}
\hline Division & \multicolumn{1}{c}{ Program name } \\
\hline Event & $\begin{array}{l}\text { Citizen Festival Group (Citizen Dance Performance Group, } \\
\text { Citizen Dance Performance Group), 2018 Seoullo Board } \\
\text { Game Competition, Seoullo Korean Mill Sori Garden } \\
\text { Creation, 〈Puppet Show〉 Citizen Parade Group }\end{array}$ \\
\hline Education & $\begin{array}{l}\text { House brewing, traditional liquor making, chihwa line, } \\
\text { pressurized wine glass making, traveler's study, self-esteem } \\
\text { class, appraisal class, body class (yoga), boutique art class, } \\
\text { plant miniature essay class, book club, garden culture class, } \\
\text { green sky chorus class, Manli-dong Children's DJing Club }\end{array}$ \\
\hline Exhibition & \multicolumn{1}{c}{ - } \\
\hline Show & Seoullo Story Class, Seoulro Stroll with Commentary \\
\hline tary & Seoullo Green Day, Seoullo Family Gardening Class \\
\hline $\begin{array}{c}\text { Group } \\
\text { service }\end{array}$ & Seoullo Family Gardening Class \\
\hline Individual \\
service
\end{tabular}

Source: http://seoullo7017.co.kr 
Table 2. Behavior type

\begin{tabular}{|c|c|c|c|}
\hline & Division & Behavior & Content \\
\hline \multicolumn{2}{|c|}{ Dynamic behavior } & Ride, play, run, walk & $\begin{array}{l}\text { Move. } \\
\text { A variety of vehicles and activities move the location. }\end{array}$ \\
\hline \multicolumn{2}{|c|}{ Static behavior } & Sit, lay down, breathe, think, appreciate, wait & No activity of the body occurs and no shift of position. \\
\hline \multirow{2}{*}{$\begin{array}{l}\text { Basicbe } \\
\text { havior } \\
\text { type }\end{array}$} & Communication & Talk, listen, see, meet & $\begin{array}{l}\text { Anyone can see and enjoy what happens in the space. } \\
\text { Meeting with acquaintances causes conversation. } \\
\text { listen to the sounds around you or music. }\end{array}$ \\
\hline & Energy source & Eat, drink & Human instinct desire \\
\hline \multicolumn{2}{|c|}{$\begin{array}{l}\text { Information communication } \\
\text { service behavior }\end{array}$} & $\begin{array}{l}\text { Share, post, record, } \\
\text { Find [Search], recommend } \\
\text { Reservation, take a picture }\end{array}$ & $\begin{array}{l}\text { Internet use and participation in internet games } \\
\text { Find information and content related to space. } \\
\text { Share and interact with information from Internet users. } \\
\text { Record your thoughts with photos or text and post them online. }\end{array}$ \\
\hline
\end{tabular}

Source: Woo and Suh(2020)를 참고하여 연구자 재구성

을 나타내는 말을 뜻하는 동사는 도출된 키워드의 특성에 따라 유형화하였다. 구분한 유형은 동적, 정적, 소통, 에너지원, 정보 통신서비스 행태이다(Table 2 참조).

(2) 개체명 분류 분석(Named-Entity Recognition)

데이터 수집 시 높은 빈도로 도출된 상위 100 개의 키워드 중 명사와 형용사는 텍스톰에서 지원하는 개체명 인식 프로그램 을 활용하여 행태에 영향을 미치는 세부적인 요소를 살펴보았 다. 개체명은 기존 연구(Woo and Suh, 2020)를 참고하여 스포 츠 및 레저, 문화·예술, 자연자원, 여가, 형용사로 분류하고 재 수정하였다(Table 3 참조).

(3) 키워드 연결망 분석(N-GRAM)

도출된 키워드와 키워드간의 연결관계를 살펴봄으로써 도출 된 키워드의 의미를 파악하였다.

\section{3) 소셜 네트워크 분석(Social Network Analysis)}

(1) 데이터의 네트워크 구조 연결정도 수준 분석

전체 키워드의 연결정도를 수치로 확인(밀도분석)하였다. 이 과정에서 각 시기별로 분석에 활용한 데이터의 전반적인 연

Table 3. Named-entity recognition

\begin{tabular}{l|c|c|c|c}
\hline \multicolumn{4}{c}{ Named-entity recognition } \\
\hline \multirow{2}{*}{$\begin{array}{c}\text { Existing } \\
\text { research }\end{array}$} & Culture $\cdot$ arts & People & Dates & $\begin{array}{c}\text { Local and } \\
\text { infrastructure }\end{array}$ \\
\cline { 2 - 5 } & Adjectives & Leisure & $\begin{array}{c}\text { Natural } \\
\text { resources }\end{array}$ & Sports and leisure \\
\hline \multirow{4}{c}{$\downarrow$} \\
\hline \multirow{3}{*}{ Researcher Named-entity recognition } \\
\cline { 2 - 5 } & Culture $\cdot$ arts & Sports and leisure & Natural resources \\
\hline
\end{tabular}

Source: Woo and Suh, (2020)를 참고하여 연구자 재구성
결관계의 양, 기본구조를 파악하였다(Marsden, 2002).

(2) 데이터의 중심성 분석(Network Centrality)

(1) 연결중심성 분석(Degree Centrality)

연결중심성 분석의 지표를 통해 전체 네트워크 중심에 위치 하는 파워가 강하고 의사결정에 영향력을 행사하는 행태를 파악할 수 있다(Friedkin, 1993).

(2) 매개중심성 분석(Betweenness Centrality)

매개중심성 지표는 중재자로서의 역할에 중점을 두고 있다. 이 지표는 네트워크에서 키워드의 잠재적 통제 혹은 영향력을 의미한다(Marsden, 2002). 즉, 매개중심성 분석을 통해 직접 연결되어 있지 않은 행태 간의 중개 역할을 하는 노드를 찾을 수 있다.

\section{4) 데이터에 대한 통계적 유의성 검정}

텍스트마이닝과 소셜 네트워크 분석 시 기초자료로 사용된 데이터의 밀도가 0 이라는 가정하에 가설검정을 수행하였다. 소 셜 네트워크 분석에 사용되는 데이터는 무작위 표본이 아닌 경 우가 많은 데이터의 특성으로 전통적 통계기법에서 사용되는 유의성 검정 절차를 따를 수 없는 한계가 있다. 이러한 한계를 극복하기 위한 방법으로 표본을 반복적으로 복원추출하여 추 정하고자 하는 통계량의 경험적 분포를 생성하는 Ucinet6를 도 구로 부트스트랩기법(Gwak, 2017)을 사용하였다.

\section{III. 결과 및 고찰}

\section{1. 데이터 수집 결과}

데이터를 수집한 서울로 7017이 시민에게 개방된 2017년 6 월부터 2020년 5 월까지 블로그 수집 결과는 Table 4 와 같이 총 20,290 건이 수집되었고, 도출된 키워드는 7,533 개이다. 
Table 4. BLOG analysis data amount

\begin{tabular}{c|c|c|c}
\hline Destiation & Data amount & Keyword count & Total \\
\hline Seoullo 7017 & 20,290 & 7,533 & $599 \mathrm{~KB}$ \\
\hline
\end{tabular}

이중 주제어와 관련된 서울로 7017 , 서울시, 서울역 등을 제 외하고, 상위 키워드 100 개가 분석에 사용되었다. 가장 많은 빈 도로 도출된 키워드는 Table 5 와 같이 '야경', '걷다', '보다' 순 이다. 야경은 야경명소, 서울야경, 야경보기 좋은 서울로 7017 , 야경촬영 등과 좋다, 멋지다, 아름답다 등의 형용사와 연관관계 가 있어 긍정적인 요소로 표현되었다. 또한, 가볼만한 곳, 도보 관광, 여행, 도심여행코스, 서울여행, 랜드마크 등의 키워드 도 출로 여행목적지로서 인식하고 있음을 알 수 있다.

시민들의 참여를 유도하는 프로그램 및 행사 관련 키워드는 실제 운영되었거나 운영되고 있는 프로그램명이 정확하게 도 출되지 않았지만 공연, 겨울축제, 정원박람회, 전시, 4 계절 축 제, 보드게임, 행사 등 프로그램 및 행사 관련 키워드가 다양하 게 도출되었다. 한편, 부정적인 키워드로 아쉽다. 부족하다, 죽 었다, 무섭다, 우려, 추락사고 등이 나타났으며, 2019년 12월 중
국 우한에서 발생한 이후 전 세계로 확산된 코로나바이러스 (SARS-CoV-2)로 코로나도 키워드로 도출되어 코로나가 기존 의 이용행태 변화에 영향을 미친다는 것을 알 수 있다.

\section{2. 텍스트 마이닝 분석}

\section{1) 주요 행태 키워드 분석}

데이터 수집에서 높은 빈도로 도출된 상위 100 개의 키워드 중 기존 연구(Woo and Suh, 2020)를 참조하여 사람의 움직임 을 나타내는 말을 뜻하는 동사를 동적, 정적, 소통, 에너지원, 정보통신서비스 행태로 구분하였으며, Table 6 과 같다. 주요 행 태 키워드를 살펴보면 구분한 유형별로 각 한 가지 키워드만 도출되어 서울로 7017 에서 다양한 행태가 일어나지 않는 것을 알 수 있다.

각 분류별로 도출된 키워드를 살펴보면, 동적 행태는 '걷다', 정적 행태는 '앉다', 소통행태는 '보다', 에너지원 행태는 '먹다', 정보통신서비스 행태는 '사진을 찍다'이다. '걷다'는 산책과 같 은 의미로 서울로 7017 에서 가장 빈도가 높은 행태로 나타났다.

Table 5. Frequency of behavior-related keywords

\begin{tabular}{|c|c|c|c|c|c|c|c|c|}
\hline & 키워드 & 빈도 & 키워드 & 빈도 & 키워드 & 빈도 & 키워드 & 빈도 \\
\hline \multirow{25}{*}{$\begin{array}{c}\text { 서울로 } \\
7017\end{array}$} & 야경 & 987 & 찾다 & 134 & 안전 & 69 & 재탄생 & 41 \\
\hline & 걷다 & 914 & 개장 & 130 & 아름답다 & 68 & 겨울축제 & 40 \\
\hline & 보다 & 800 & 공원 & 127 & 프로젝트 & 67 & 정원박람회 & 40 \\
\hline & 아쉽다 & 798 & 찍다 & 126 & 시민 & 67 & 조명 & 40 \\
\hline & 코로나 & 480 & 아스팔트길 & 117 & 즐기다 & 63 & 풍경 & 39 \\
\hline & 좁다 & 420 & 사진 & 107 & 추락사고 & 62 & 하이라인 & 39 \\
\hline & 볼거리 & 349 & 앉다 & 106 & 맛집 & 62 & 엘리베이터 & 38 \\
\hline & 사람길 & 337 & 산책 & 106 & 나들이 & 60 & 프로그램 & 38 \\
\hline & 잠깐 & 336 & 공중정원 & 105 & 주변 & 60 & 랜드마크 & 37 \\
\hline & 식물 & 333 & 17 개 & 102 & 먹거리 & 57 & 광장 & 36 \\
\hline & 보행길 & 308 & 남대문 & 101 & 나무 & 54 & 한가하다 & 36 \\
\hline & 좋다 & 296 & 기대하다 & 89 & 의자 & 53 & 전시 & 35 \\
\hline & 혼자 & 262 & 식충식물 & 89 & 예쁘다 & 52 & 추천 & 35 \\
\hline & 고가도로 & 257 & 시간여행 & 82 & 휑하다 & 48 & 공간 & 34 \\
\hline & 부족하다 & 218 & 연결 & 82 & 구경 & 48 & 트램펄린 & 34 \\
\hline & 남대문시장 & 201 & 고가공원 & 79 & 먹다 & 48 & 촬영 & 34 \\
\hline & 1970년 & 179 & 명소 & 78 & 죽었다 & 48 & 물놀이 & 33 \\
\hline & 위험 & 179 & 여행 & 78 & 비오는날 & 48 & 4계절축제 & 32 \\
\hline & 데이트 & 171 & 도심 & 77 & 공연 & 48 & 시설 & 31 \\
\hline & 가볼만한 곳 & 163 & 코스 & 77 & $\frac{777}{\bar{\lambda}}$ & 45 & 보드게임 & 30 \\
\hline & 도보관광 & 160 & 멋지다 & 76 & 바꾸다 & 44 & 명동 & 29 \\
\hline & 새롭다 & 157 & 활력 & 75 & 머물다 & 44 & 하늘 & 29 \\
\hline & 추억 & 153 & 우려 & 73 & 무섭다 & 43 & 행사 & 29 \\
\hline & 그늘 & 148 & 맛집 & 71 & 작다 & 42 & 뜨겁다 & 26 \\
\hline & 도시재생 & 138 & 서울여행 & 70 & 짧다 & 41 & 변신 & 26 \\
\hline
\end{tabular}


Table 6. Behavioral verb classification

\begin{tabular}{|c|c|c|}
\hline \multicolumn{2}{|c|}{ Behavior } & Keyword \\
\hline \multicolumn{2}{|c|}{ Dynamic behavior } & walk \\
\hline \multicolumn{2}{|c|}{ Static behavior } & Sit \\
\hline \multirow{2}{*}{$\begin{array}{l}\text { Basic } \\
\text { behavior type }\end{array}$} & Communication & See \\
\hline & Energysource & eat \\
\hline \multicolumn{2}{|c|}{ Information Communication Service Behavior } & Taking pictures \\
\hline
\end{tabular}

정적행태는 '앉다'가 도출되었고, 소통형태로 도출된 '보다'는 야경, 경치, 경관, 식물, 차량, 공연 등과 연관관계가 있어 시각 적인 볼거리를 의미한다. 에너지원 행태는 '먹다'가 도출되었고, 정보통신 행태인 '사진을 찍다’는 보다, 야경, 경관, 경치, 인증샷 등과 연관관계가 있어 소통행태와 연결되는 행태라고 볼 수 있다.

\section{2) 개체명 분류 분석}

데이터 수집 시 높은 빈도로 도출된 상위 100 개의 키워드 중 명사와 형용사는 주요 행태에 영향을 미치는 요소로 기존 연구 (Woo and Suh, 2020)를 참고하여 스포츠 및 레저, 문화·예술, 자연자원, 여가, 형용사로 분류하고 재수정하였다.

주요 행태에 영향을 미치는 요소는 Table 7과 같이 스포츠 및 레저 관련 키워드는 보드게임, 물놀이, 트램펄린 등이 나타 났고, 문화 - 예술관련 키워드는 공연, 프로그램, 캠페인, 겨울 축제, 정원박람회, 전시, 4 계절축제, 행사, 자연자원 관련 키워 드는 식물, 꽃, 하늘, 나무, 식충식물, 여가와 관련된 키워드는 야경, 산책, 촬영, 데이트, 형용사는 아쉽다, 좋다, 멋지다, 아름 답다, 즐기다, 예쁘다, 휑하다, 무섭다, 작다, 짧다, 한가하다, 뜨 겁다가 나타났다. 상위 100 개의 키워드 이외에 도출된 형용사 는 북적거리다, 느끼다, 발견하다, 감상하다, 휴식하다, 힐링하 다, 매력있다 등이 있다.

\section{3) 키워드 연결망 분석}

키워드 연결망 분석은 Table 8과 같이 키워드간의 연결관계 를 통해 키워드가 도출된 원인을 파악할 수 있다. 또한, Figure 1 과 같이 주요 키워드 중 긍정과 부정으로 구분하여 키워드간

Table 7. Named-entity recognition

\begin{tabular}{c|c}
\hline Sports and leisure & Koard game, water play, trampoline \\
\hline Culture $\cdot$ art & $\begin{array}{c}\text { Performances, programs, campaigns, winter } \\
\text { festivals, garden fairs, exhibitions, four seasons } \\
\text { festivals, events }\end{array}$ \\
\hline Natural resources & Plant, flower, sky, tree, carnivorous plant \\
\hline Free time & Night view, walk, photoshoot, date \\
\hline Adjective & $\begin{array}{c}\text { Sorry, good, cool, beautiful, enjoyable, pretty, } \\
\text { straightforward, scary, small, short, free, hot }\end{array}$ \\
\hline
\end{tabular}

Table 8. Keyword associations(N-garm)

\begin{tabular}{|c|c|c|c|c|}
\hline & 키워드 & & 키워드 & 빈도 \\
\hline 1 & 야경 & $\leftrightarrow$ & 보다 & 125 \\
\hline 2 & 서울로7017 & $\leftrightarrow$ & 걷다 & 99 \\
\hline 3 & 서울역 & $\leftrightarrow$ & 볼거리 & 93 \\
\hline 4 & 걷다 & $\leftrightarrow$ & 보행길 & 73 \\
\hline 5 & 식물 & $\leftrightarrow$ & 보다 & 70 \\
\hline 6 & 코로나 & $\leftrightarrow$ & 걷다 & 56 \\
\hline 7 & 볼거리 & $\leftrightarrow$ & 찾다 & 48 \\
\hline 8 & 잠깐 & $\leftrightarrow$ & 걷다 & 43 \\
\hline 9 & 걷다 & $\leftrightarrow$ & 좋다 & 38 \\
\hline 10 & 아쉽다 & $\leftrightarrow$ & 식물 & 36 \\
\hline 11 & 좁다 & $\leftrightarrow$ & 사람길 & 33 \\
\hline 12 & 걷다 & $\leftrightarrow$ & 좁다 & 31 \\
\hline 13 & 볼거리 & $\leftrightarrow$ & 아쉽다 & 30 \\
\hline 14 & 보다 & $\leftrightarrow$ & 남대문시장 & 30 \\
\hline 15 & 보다 & $\leftrightarrow$ & 혼자 & 29 \\
\hline 16 & 서울로7017 & $\leftrightarrow$ & 아스팔트길 & 28 \\
\hline 17 & 도심 & $\leftrightarrow$ & 여행 & 28 \\
\hline 18 & 야경 & $\leftrightarrow$ & 새롭다 & 27 \\
\hline 19 & 개장 & $\leftrightarrow$ & 새롭다 & 27 \\
\hline 20 & 부족하다 & $\leftrightarrow$ & 뜨겁다 & 26 \\
\hline 21 & 그늘 & $\leftrightarrow$ & 부족하다 & 26 \\
\hline 22 & 낮 & $\leftrightarrow$ & 한가하다 & 26 \\
\hline 23 & 아스팔트길 & $\leftrightarrow$ & 아쉽다 & 25 \\
\hline 24 & 명소 & $\leftrightarrow$ & 방문 & 24 \\
\hline 25 & 서울시 & $\leftrightarrow$ & 가볼만한 곳 & 24 \\
\hline 26 & 프로그램 & $\leftrightarrow$ & 공연 & 24 \\
\hline 27 & 북적거리다 & $\leftrightarrow$ & 코로나 & 24 \\
\hline 28 & 바꾸다 & $\leftrightarrow$ & 코로나 & 24 \\
\hline 29 & 코로나 & $\leftrightarrow$ & 북적거리다 & 24 \\
\hline 30 & 혼자 & $\leftrightarrow$ & 걷다 & 22 \\
\hline
\end{tabular}

의 연결 관계를 시각화하였다.

먼저 긍정적인 의견의 키워드 연결망을 살펴보면, 서울로 7017이 만들어져서 좋다, 걷기 좋은 것, 가볼만한 곳, 야경이 예 쁘다 등의 내용이 주를 이루고 있고, 부정적인 의견의 키워드 연결망을 살펴보면 낮에 뜨겁다, 그늘이 부족하다, 아스팔트길 이 아쉽다, 볼거리가 부족하다, 길이 좁다, 의지가 부족하다 등 의 내용이 도출되었다. 


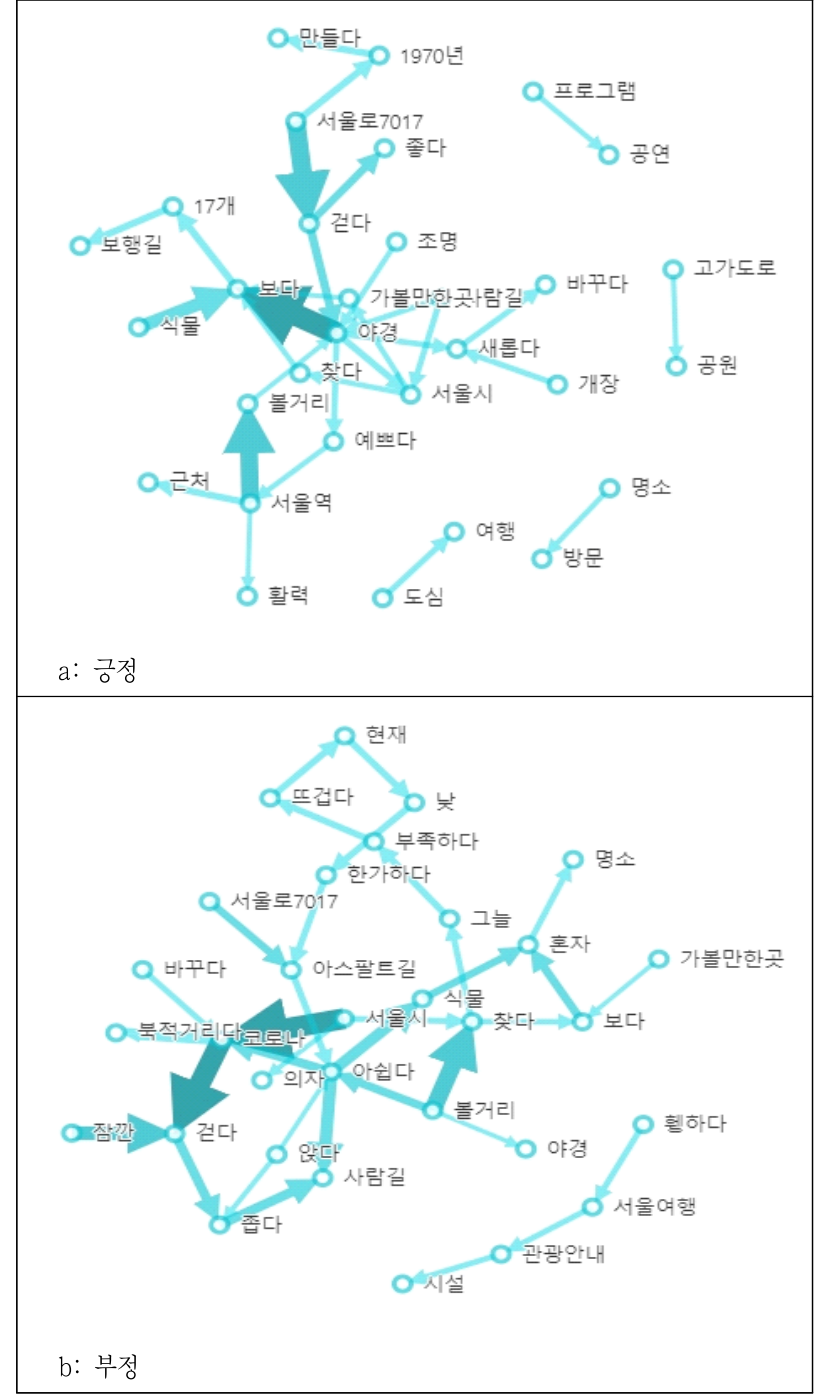

Figure 1. Keyword associations(N-garm)

키워드 연결망 분석을 통해 중점적으로 살펴볼 점은 주요 행 태 키워드 분석 시 도출된 '앉다'와 '먹다'는 연결망 분석을 통 해 서울로 7017에서 일어나는 주요 행태가 아니라는 것이다. '앉다'는 서울로 7017에서 방문객이 원하는 행태이지만, 앉을 수 있는 조건이 충분히 지원되지 않고 있어 높은 빈도로 나타났다.

또한, 에너지원 행태인 '먹다'는 남대문 시장, 명동, 근처에서 찾다 등의 키워드와 연관관계가 있어 서울로 7017에서 먹는 행 태가 발생하는 것이 아니라, 주변 다른 장소에서 먹는 행태가 일어나는 것을 알 수 있다.

또한, 키워드 연결망 분석에서 특이한 점은 코로나19로 인하 여 공공다중이용시설 및 집단 활동이 제한되면서 혼자 여행하 기 좋은 곳, 혼자 산책하기 좋은 곳으로 인식되고 있다는 점이 다. 데이트나 친구와 방문하였을 시 볼거리가 부족하고 앉을 곳이 부족하여 잠깐 머물다가는 행태에 부정적인 평가가 도출 되었는데, 코로나 19 로 인하여 혼자 방문하기 좋은 곳으로 인식
이 변화하였다는 것을 알 수 있다.

빈도분석 시 빈도가 높은 상위 100 개의 키워드안에 시민들 의 참여를 유도하는 프로그램 및 행사 관련 키워드가 다양하게 도출되었는데, 키워드간의 연결관계가 나타나지 않았고 '볼거 리를 찾다 등의 내용이 언급되어 프로그램에 대한 인지도가 부족하다고 볼 수 있다.

주요 키워드 연결관계 이외에 식물이 죽었다, 볼거리가 부족 하여 휑하다, 너무 인위적이다, 삭막하다, 잠깐 들르기 좋은 곳, 데이트코스 추천, 남대문시장과 함께 가기 좋은 곳 등의 내용 이 나타났다.

\section{3. 소셜 네트워크 분석}

\section{1) 네트워크 구조 연결수준 분석}

네트워크 구조의 연결정도 수준을 파악하기 위하여 네트워 크를 구성하는 키워드(노드)간의 연결정도(링크)의 합과 밀도 를 분석한 결과, 연결의 합은 Figure 2와 같이 총 103,704이고, 밀도는 0.1047 로 나타났다. 서울로 7017 의 네트워크 연결수준 과 데이터 밀도의 크기가 크고 응집성을 가지고 있다고 보기 어렵다. 즉, 서울로 7017 에서 다양한 행태가 일어나고 있지 않 으며, 행태와 행태간의 연결이 이루어지지 않는다는 것을 알 수 있다.

\section{2) 데이터의 중심성 분석}

도출된 키워드의 속성을 파악하여 가장 중심적인 행태를 분 석하기 위하여 다른 키워드와 연관관계가 가장 많은 키워드를 분석한 결과, Table 9와 같이 '야경', '걷다', '보다', '코로나' 순 으로 나타났다. 즉, 서울로 7017에서 이루어지는 행태 중 야경 은 방문객에게 가장 주목받는 요소라고 볼 수 있다. 즉, '야경' 은 서울로 7017에서 가장 중요 행태이면서 다른 행태를 발생시 킬 수 있는 잠재력을 가지는 요소가 될 수 있다.

또한, 서울로 7017을 이용 시 만족도를 높일 수 있는 영향력 을 가지고 있는 키워드는 '코로나'가 가장 높게 나타났다. 코로

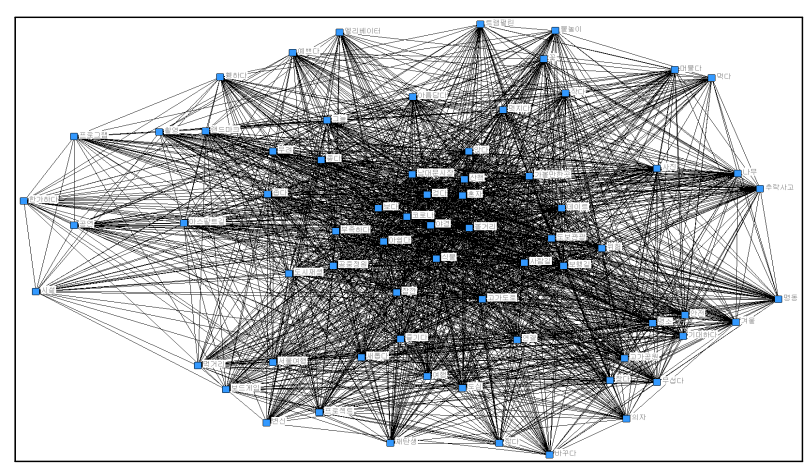

Figure 2. Network connection level Total connections : 103,704 Density: 0.1047 
Table 9. Network centrality

\begin{tabular}{c|c|c|c|c}
\hline & \multicolumn{2}{|c|}{ 중심성 } & \multicolumn{2}{c}{ 매개중심성 } \\
\hline 1 & 야경 & 9.871 & 코로나 & 0.746 \\
\hline 2 & 걷다 & 8.566 & 남대문 시장 & 0.730 \\
\hline 3 & 보다 & 8.417 & 야경 & 0.570 \\
\hline 4 & 코로나 & 8.343 & 볼거리 & 0.570 \\
\hline 5 & 잠깐 & 5.005 & 그늘 & 0.546 \\
\hline
\end{tabular}

나19와 같은 상황에서 사람들이 산책 등을 할 수 있는 시설, 여 러 가지 볼거리 증대 등을 통하여 더 다양한 행태가 도출될 수 있고, 이용객의 만족도를 높일 수 있다.

남대문시장도 매개중심성이 높게 나타났는데, 서울로7017남대문시장이 산책코스, 가족여행 코스로 긍정적인 내용이 많 았으며, 이를 적극 활용하면 방문객의 만족도를 높일 수 있는 요소가 될 수 있을 것이다. 또한, '그늘'은 정적 행태인 '앉다'와 연관이 있는 키워드로 앉는 행태를 발생시킬 수 있는 요소로 활용될 수 있다.

3) 데이터에 대한 통계적 유의성 검정

가설검정 결과를 살펴보면, Table 10 과 같이 표본평균의 평 균은 0.1061 (average bootstrap density)이고, 표준오차는 0.2 920(estimated standard error for density)이며, 검정통계량 (z-score) 은 5.9533이다. 절대값으로 이 값보다 큰 값이 나올 확 률은 0.002(proportion of absolute differences as large as observe)로 유의수준 $0.01 \%$ 를 기준으로 통계적으로 유의하다. 이에 서울로 7017의 네트워크 구조를 분석하는데 활용한 네트 워크 데이터의 밀도가 0 이라는 귀무가설을 기각한다는 결론 내 릴 수 있다.

\section{IV. 결론}

본 연구는 국내 최초의 공중보행로인 서울로 7017의 이용특 성을 파악하는 하나의 척도로 의미가 있다. 이에 서울로 7017 의 이용객이 자율적으로 서술한 블로그를 분석하여 이용현황 을 파악하고, 서울로 7017의 이용행태 및 개선방안을 제시하는 것을 목적으로 하였다.

Table 10. Significance test

\begin{tabular}{c|c}
\hline Verification & Value \\
\hline Density & 0.1047 \\
\hline Average bootstrap density & 0.1061 \\
\hline Estimated standard error for density & 0.2920 \\
\hline Z-score & 5.9533 \\
\hline Proportion of absolute differences as large as observed & 0.0002 \\
\hline
\end{tabular}

분석 결과, 서울로 7017 이용의 행태적 특성은 다음과 같다. 1. 서울로 7017의 주요 행태는 각 분류별로 동적 행태는 '걷 다', 정적행태는 '앉다', 소통행태는 '보다, 에너지원 행태는 '먹 다', 정보통신서비스 행태는 '사진을 찍다'이다.

동적 행태인 '걷다'는 산책과 같은 의미로 서울로 7017에서 가장 빈도가 높은 행태로 나타났다고 소통형태로 도출된 '보다' 는 야경, 경치, 경관, 식물, 차량, 공연 등과 연관관계가 있어 시 각적인 볼거리를 의미한다. 특히, '야경'은 서울로 7017에서 주 요 행태에 영향을 미치는 중요 요소이면서 다른 행태를 발생시 킬 수 있는 잠재력을 가지는 요소가 될 수 있다. 이에 야경을 즐길 수 있는 다양한 프로그램 및 시설의 개선이 필요하다. 정 보통신 행태인 '사진을 찍다'는 보다, 야경, 경관, 경치, 인증샷 등 과 연관관계가 있어 소통행태와 연결되는 행태라고 볼 수 있다.

정적 행태인 '앉다'는 서울로 7017에서 방문객이 원하는 행 태이지만 활발하게 이루어지지 않아 부정적인 내용으로 주요 키워드로 도출되었고, '먹다'는 서울로 7017의 주변지역에서 일 어나는 행태로 서울로 7017의 주요 행태라고 볼 수 없다. 즉, 서울로 7017의 주요 행태는 '걷다', '보다(경치, 야경 등)', '사진 을 찍다로 다양한 행태가 나타나지 않았고, 행태간의 연결이 되지 않아 잠깐 머무르는 행태가 주를 이루었다.

2. 서울로 7017의 주요 행태에 영향을 미치는 요소는 스포츠 및 레저, 문화 - 예술, 자연자원, 여가로 구분하였는데, 공연, 프 로그램, 캠페인, 겨울축제, 정원박람회, 전시, 4 계절축제, 행사 등 문화 - 예술과 관련된 키워드가 가장 다양하게 나타나 주요 행태에 영향을 미치는 요소를 알 수 있다.

분석 시 시민들의 참여를 유도하는 프로그램 및 행사 관련 키워드는 공연, 겨울축제, 정원박람회, 전시, 4 계절축제, 보드게 임, 행사 등이 도출되었지만 키워드간의 연결관계가 나타나지 않았고, '볼거리를 찾다' 등의 내용이 언급되어 프로그램에 대 한 인지도가 부족하다고 볼 수 있다. 이에 모든 계층을 아우를 수 있는 프로그램의 개발 및 홍보가 필요하다. 또한, 프로그램 및 행사를 통해 이용객이 원하는 행태인 '앉다', '먹다'의 행태 를 일어나게 하면서 동시에 잠깐 머무는 것이 아니라, 장시간 머무르며 이용객의 인지, 정서, 행동적 요소 등의 향상을 기대 할 수 있다. 즉, 문화·예술과 관련된 여러 가지 프로그램 및 축제를 이용객의 요구에 맞는 프로그램을 개설하고, 적극적으 로 알린다면 주요 행태가 더 활발하게 일어나게 할 수 있을 것 이다.

3. 서울로 7017의 이용객들이 원하는 주요 행태는 정적 행태 인 '앉다'이다. 정적 행태는 물리 환경이 좋은 조건으로 제공될 때 장시간 머무름이 가능해지는 것으로 앉아서 머무르기와 함 께 좋은 조건이 제공되면 다른 활동이 뒤따르게 되며, 그 공간 을 활력있고 의미 있게 만드는 가치를 제공한다(Choi, 2009). 그러나 길이 좁고 그늘 및 의자가 부족하여 아쉽다는 내용이 부정적인 의견의 주를 이루고 있다. 이에 그늘, 벤치 등 앉는 
행태가 일어날 수 있는 시설을 개선하여 방문객의 요구를 충족 시킬 수 있을 것이다.

4. 서울로 7017의 행태변화의 특이점으로 코로나19로 인하여 공공다중이용시설 및 집단 활동이 제한되면서 혼자 여행하기 좋은 곳, 혼자 산책하기 좋은 곳으로 인식되고 있다는 점이다. 데이트나 친구와 방문하였을 시 볼거리가 부족하고 앉을 곳이 부족하여 잠깐 머물다가는 행태에 부정적인 내용에서 코로나 19 로 인하여 혼자 방문하기 좋은 곳으로 인식이 변화하였다는 것 을 알 수 있다. 또한, 코로나는 다른 행태를 발생키길 수 있는 잠재력을 가지는 요소가 될 수 있다. 또한, 코로나, 걷다, 볼거 리도 영향력있는 요소로 나타나 코로나19와 같은 상황에서 사 람들이 산책 등을 할 수 있는 시설, 여러 가지 볼거리 증대 등 을 통하여 더 다양한 행태가 도출될 수 있고, 이용객의 만족도 를 높일 수 있다.

이밖에도 남대문 시장과의 연결, 볼거리 확대, 화분의 관리 를 통해 서울로 7017에 잠깐 머무르는 행태를 개선할 수 있다.

5. 분석에 활용한 데이터의 밀도가 0 이라는 가정하에 가설검 정을 수행한 결과, 유의수준 $0.01 \%$ 를 기준으로 통계적으로 유 의하다.

본 연구의 대상지는 근대 산업화의 상징이자 도시 산업 인프 라인 서울역 고가를 시민의 휴식과 보행을 위한 도심공원으로 재조성한 장소이다(Son, 2018). 그러나 분석결과, 다양한 행태 가 일어나지 않고 있으며, 주요 행태를 방해하는 요소가 도출 되었다. 이러한 연구 결과를 통해 서울로 7017의 이용행태를 파악하고 공간체계 및 시설 개선의 계획을 수립할 수 있을 것 이다.

본 연구는 블로그를 이용하는 이용객의 의견을 토대로 분석 이 이루어졌기 때문에 서울로 7017 을 이용하는 모든 이용객의 의견이라고 보기 어렵다. 또한, 블로그 이외의 소셜 네트워크 (페이스북, 트위터 등)는 사이트 보안정책상 수집해올 수 있는 데이터의 기간과 양에 한계가 있다. 이에 최대 일주일 기간의 데이터를 가져올 수 있으며, 그 양은 본 연구의 목적을 달성하 기에 적은 양으로 데이터 수집 대상을 확대하지 못한 한계점이 있다. 이에 후속연구에서 블로그를 이용하지 않는 이용객의 이 용 행태를 추가하여 분석하는 것이 필요하다.

\section{References}

1. Cha, D. W., J. W. Song., J. W. Choe and C. H. Oh(2020) Immig- ration plant characteristics of Seoullo 7017, as artificial foundation greening area, after completion 1 year, The Korea Society For Environmental Restoration and Revegetation Technology 23(1): 15- 36.

2. Choi, H. K.(2009) The Instrumental Proposal That is Based on The Human Behavior and Space Trait. Master's Thesis. Sungkyunkwan University.

3. Choung, E. H.(2018) A study on urban tourism through urban regeneration: Focusing on the case of Seoullo 7017, Journal of the Korean Urban Geographical Society 21(1):53-64.

4. Friedkin, N.(1993) Structural bases of interpersonal influence in group s: A longitudinal case study. American Sociological Review 58: 861-872

5. Gwak, K. Y.(2017) Social network analysis, Chungram.

6. Joo, S. H. and Y. H. Kim(2010), The cognition of design concepts for urban parks -The cases of Seoul forest, Yeouido park, and Seonyudo park ${ }^{-}$. Journal of The Korean Institute of Landscape Architecture 38(5) :53-63.

7. Kim, H. J.(2018) A Study on Cognition and Behavior of Seoullo 7017 Visitors: Focusing on Implementation of Design Concept, Master's Thesis. University of Seoul Korea.

8. Kim, J. H.(2019) An Analysis of User Satisfaction on Seoullo 7017, Master's Thesis. University of Yonsei Korea.

9. Lee, J. S. (2019) Effect of 'Seoullo 7017' on City Image and City Preference of Foreign Tourists. Master's Thesis. University of Kyunghee.

10. Marsden, P. V.(2002) Egocentric and sociocentric measures of network centrlaity. Social Networks, 24:407-422.

11. Park, S. J., W. S. Lee and J. H. Moon(2018) A study of visitor perception for Seoul-ro 7017 using IPA, Journal of Hospitality and Tourism Studies 20(3):14-22.

12. Rii, H. E. and J. H. Choi (2009) Creation and utilization of green spaces in the city from the viewpoint of urban renewal. Journal of The Korean Urban Geographical Society 12(1):1-10.

13. Son, S. S. (2018) Analysis of The Conditions and Satisfaction of the Users on to The Landscape Infrastructure of Seoullo 7017, Master's Thesis. University of Hanyang.

14. Seoullo 7017 White paper.

15. Woo, K. S. and J. H. Suh(2020) Time Series Analysis of Urban Parks Usage Patterns. Ph.D. Dissertation. University of Kyunghee.

16. Ministry of Culture, Sports and Tourism, https://www.mcst.go. kr/ kor/s_notice/press/pressView.jsp?pSe q $=17057$

17. Newdaily, http://www.newdaily.co.kr/site/data/html/2017/06/19/20 17061900069.html, 2017.06.19.

18. Newsis, https://newsis.com/view/?id=NISX20170428_0014862093\& $\mathrm{cID}=10201 \& \mathrm{pID}=10200,2017.04 .29$.

19. Seoullo7017, http://seoullo7017.co.kr/

20. Textom, http://www.textom.co.kr

21. Yonhap News, https://www.yna.co.kr/view/AKR20170629125000004? input $=11$ 95m, 2017.06.29.

22. Yonhap News, https://www.yna.co.kr/view/AKR20200518144800004? input $=11$ 95m, 2020.05.19. $\begin{array}{rll}\text { Received : } 25 & \text { August, } 2020 & \\ \text { Revised : } & 16 \text { September, } 2020 & \text { (1st) } \\ & 18 \text { September, 2020 } & \text { (2nd) } \\ 19 \text { October, 2020 } & \text { (3rd) } \\ 30 \text { October, 2020 } & \text { (4th) }\end{array}$

Accepted : 30 October, 2020 4 인익명 심사필 